\title{
Quiz Tool Within Moodle and Blackboard Mobile Applications
}

\author{
https://doi.org/10.3991/ijim.v13i08.10552
}

\author{
Aayat Shdiafat $\left.{ }^{(}\right)$, Randa Obeidallah \\ Hashemite university, Zarqa, Jordan \\ aayat@hu.edu.jo
}

\begin{abstract}
The development of a course is measured through Assessments. Tests and Quizzes measure performance and quality of course progress as well as student understanding of course contents. Most of Learning Management Systems (LMSs) provide a built in quiz tool to help instructor to design a quiz and obtain students records. Nowadays, LMSs companies provide versions (applications) that are compatible with mobile handheld devices. In this paper, we will investigate features available within quiz tool within the open source LMS Moodle and the proprietary LMS Blackboard.
\end{abstract}

Keywords-Quiz, Assessment, Moodle, Blackboard, Mobile, Application, Online, E-assessment, LMS, Learning

\section{Introduction}

Handheld devices such as: Laptops, Personal Digital Assistants (PDAs) and smart phones are becoming popular among people as they are portable and affordable wireless microcomputers with handwriting recognition technology. The evolution and continuous expansion of mobile devices has arisen the integration between the educational environment and the modern mobiles. The term mobile learning (Mlearning) refers to the use of handheld IT devices in training, learning and teaching [22]. It facilitates learners to access knowledge anytime and anywhere as well as to merge their learning experiences in a shared collaborative environment. It provides mobility of technology, Mobility of learners, and Mobility of learning [4]. M-learning is developed as an expansion of E-learning (Mobilearn 2003) and considered to be one of the newest trend in education application [29].

Currently, Learning Management System(LMS) is the core of e-learning. LMSs are deployed within institutions and organizations that are involved in education and training. LMS is supposed to support student learning and faculty teaching. Three main LMS vendors are available: Proprietary LMSs, Open-source LMSs, and Cloudbased LMSs [3]. The main differences between the three LMSs are summarized in Table1 [3] [16].

As mobile technology is being improved and expended, most of LMSs provide mobile application in addition to the desktop system to be used by student and instructor. Mobile application can prevent drawback of using web based learning [26]. 
LMSs mobile applications include built-in tool to benefit of using computer base exam [24]. It is known that e-assessment is important to develop learning method and enhance teaching strategies [18]. Different Quiz tool features are available in different LMSs mobile applications. In this paper, we will investigate features available within quiz tool in open source LMS Moodle and the proprietary LMS Blackboard.

This paper is structured as follows: Section 2 review the definition of mobile learning, section 3 introduce online mobile exam, section 4 examine Quiz features in Moodle mobile LMS and section 5 examine Quiz features in Blackboard mobile LMS, finally discussion and conclusion in section 6 .

Table 1. Differences between the three LMSs

\begin{tabular}{|c|c|c|c|}
\hline & Proprietary LMS & Open- Source LMS & Cloud-Based LMS \\
\hline Cost & $\begin{array}{l}\text { Vendors charge a license } \\
\text { fee license fee and support } \\
\text { is expensive }\end{array}$ & $\begin{array}{l}\text { If not free, OS LMSs are } \\
\text { cheaper than proprietary } \\
\text { LMSs. No need to pay for } \\
\text { maintenance and support }\end{array}$ & $\begin{array}{l}\text { Very cost-effective cost is } \\
\text { based on usage. No need } \\
\text { to pay for maintenance and } \\
\text { support }\end{array}$ \\
\hline support and service & $\begin{array}{l}\text { Vendors provide Customer } \\
\text { service support for each } \\
\text { license. }\end{array}$ & $\begin{array}{l}\text { Lack of support and service. } \\
\text { Heavy dependency on the } \\
\text { online community }\end{array}$ & $\begin{array}{l}\text { Depends on tools you } \\
\text { choose. }\end{array}$ \\
\hline Authentication & $\begin{array}{l}\text { Authentication to software } \\
\text { is usually by a Username } \\
\text { and password }\end{array}$ & $\begin{array}{l}\text { Authentication to software is } \\
\text { usually by a Username and } \\
\text { password }\end{array}$ & $\begin{array}{l}\text { Authentication might be an } \\
\text { issue: depends on tools } \\
\text { you choose but mainly use } \\
\text { Username/ password }\end{array}$ \\
\hline $\begin{array}{l}\text { Code and Innova- } \\
\text { tion }\end{array}$ & $\begin{array}{l}\text { Vendors hold possession of } \\
\text { the code.Vendors do not } \\
\text { allow users to view or alter } \\
\text { the source code. }\end{array}$ & $\begin{array}{l}\text { Vendors share the code with } \\
\text { their users. Users have the } \\
\text { freedom to share and update } \\
\text { the software without re- } \\
\text { striction. }\end{array}$ & $\begin{array}{l}\text { Vendors hold possession } \\
\text { of the code. Vendors do } \\
\text { not allow users to view or } \\
\text { alter the source code. }\end{array}$ \\
\hline Availability & $\begin{array}{l}\text { Available through compa- } \\
\text { nies that own the rights to } \\
\text { the packages. Free trial is } \\
\text { available to try before buy. }\end{array}$ & $\begin{array}{l}\text { - These are freely available to } \\
\text { download directly over the } \\
\text { net. }\end{array}$ & $\begin{array}{l}\text { Free social applications are } \\
\text { available online. Free trial } \\
\text { is available to try certain } \\
\text { tools before buy. }\end{array}$ \\
\hline Installation & $\begin{array}{l}\text { Certain LMS tools require } \\
\text { special Hardware/Software } \\
\text { installation to access and } \\
\text { use it. }\end{array}$ & $\begin{array}{l}\text { Certain LMS tools require } \\
\text { special Hardware/Software } \\
\text { installation to access and use } \\
\text { it. }\end{array}$ & $\begin{array}{l}\text { No need to install addi- } \\
\text { tional Hardware/Softwar e } \\
\text { to access and use it. }\end{array}$ \\
\hline
\end{tabular}

\section{Mobile Learning}

Mobile learning (M-learning) is another type of education technology; students can study anywhere and anytime; it is the adoption of mobile technology with pedagogical education [8]. M-learning is defined as the use of handheld computer and wireless transmission for learning and education [17]. [21] showed that the mobile learning starts through using SMS in dissemination of educational Information in Russia.

The basic features that distinguish mobile learning from traditional learning method is the ability to acquire knowledge, collaborative learning phases, the ability to combine learning content, instant need of learning and the mobility of learning [9].

According to [2], M-learning is divided into three types: formal, informal and welldirected. The formal type includes some reminder like short message or notification. 
The informal type as Facebook include exchange message and feedback to get data, and finally well-directed type uses media like video.

M-learning is a subset of Distance learning (D-learning). D-learning is term used to describe the ability to support learning for those in different geographical place [13]. M-learning is also a subset of e-learning that use electronic material in learning like internet, CDs, audio and video. The relationship between three learning system view in figure $1[5]$.

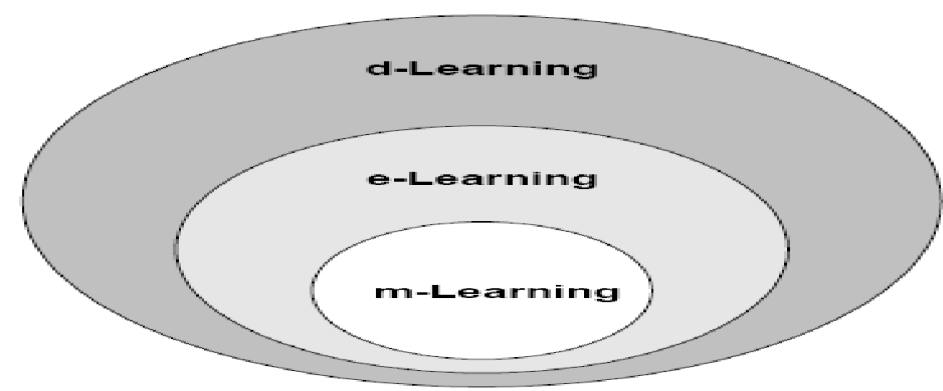

Fig. 1. The Place of M-Learning as Part of E-Learning and D-Learning [5]

M-learning is more preferable due to flexibility to access course content, download lesson notes, submit an assignment, quiz and any other learning activity at any time from mobile devices [10] [1]. In order to design a good mobile learning project, five points are considered: Technology should be accessed anytime and anywhere, holding the technology, connecting to internet via mobile phone connectivity or wireless connection, integrating mobile learning by combining some features, and finally the education institution must support good course content suitable with mobile format [14]. In addition, availability of a mobile learning tool is a must which is a tool specifically designed for mobile learning [23], and mobile learning platform which include wireless network, resource platform and mobile device [30].

[25] designed an android platform application that is integrated with Moodle, the project includes design and implementation for tool in m-learning depending on Moodle, the proposed project is more flexibility, mobility and convenient than traditional e-learning method.

\section{Online Mobile Exam}

Online exam has spread rapidly in education institution, due to benefits of using computer base exam for both student and instructor such benefits are: reduce cost, reduce errors, and reduce stress when have online exam [24]. Online exam known as online assessment or/and computer based exam mean the use of a system to evaluate student achievement in the course. The objective for using e-assessment is to develop learning method and still enhance teaching strategies [18]. 
M-learning also include an assessment tool as part of their application. Many projects were designed by researchers to provide Online exam mobile application. Quizzler, M-quiz are quiz systems used in both PCs and mobile. These systems were developed by Victoria University of Wellington. CosyQTI developed by university of Piraeus, and C-POLMILE developed by the university of Birmingham for multiple choice question [20]. Mobi-exam is another example of such applications, it was used by [28] study to achieve mobile exam, the study focus on the development of online exam applied in mobile devices or PCs. The study showed that using such applications provide more flexible, simply, quickly online exam technique. [11] produce a prototype system called MES Mobile Exam System that is available for IOS and Android.

[27] proposed a model for e-exam in mobile devices named Time Adaptive for Mobile E-Exam(TAMEx). The researchers handled the time factor during the exam. This model is based on wireless connection (WLAN IEEE802.11) and RSSI that help to give student extra time if any loss of connection happens during exam, according to result: this model increase reliability of e-exam.

Another application called HTML5 application is used for mobile test; the application depends on Sencha Touch framework. It is suitable for IOS, Android, windows phone and Blackberry. The design of HTML5 app is based on MVC (Model View Controller) [6]. iQuiz tool proposed by [19] and adopted with Moodle to apply quiz, they try to solve limitations in Moodle quiz and iAssign package which supported by Moodle. The limitations as they mention are authoring not simple, iAssign integrated with Moodle without questionnaires, quiz database and questionnaires data not integrated in search tool. iQuiz add new question types, the ability to share and reuse the quiz resources.

Online mobile exam has drawback concentrated in security [12] and cheating. The Moodbile project created by [7] to enhance security of exam in mobile learning. Many weakness point that effect exam security were considered to achieve security in open source learning management system.

[15] Proposed a theoretical model for smartphone devices to authenticate the identity of students before and during the e-assessment session. The proposed model combined biometric techniques (fingerprint and facial recognition) to control the process of student's authentication.

In this paper we will consider Moodle and Blackboard mobile applications and study quiz features within these two applications.

\section{Quiz Features in Moodle Mobile LMS}

One of the most famous open source LMS is Moodle, with $143,205,877$ users in 228 countries [Moodle, 2018]. Moodle is a free open source learning management system application that is adopted by international education institutions. It is available in 35 languages. Moodle provide a blended learning approach. Due to the revolutionary of mobile technology, Moodle provide a mobile application that is compatible with IOS and Android platforms. Through Moodle mobile, student and teacher can 
easily access course material, easily upload file with different types, view forum discussion, glossary and course plan, reminder and notifications are also available, Moodle app also deliver quiz and assignment. Moodle is an HTML5 web application, need internet connection to provide their services while its provide some offline features. (Moodle,2018). Moodle mobile app works on devices running Android 4.4+ and IOS $6+$. The Moodle mobile quiz require Moodle 3.1 onwards. Or install required plugins for older versions. Plugins are Templates generated when user open the plugin in app, Templates downloaded when user login, or Pure Java script plugins. The Moodle mobile app is an application used by both students and instructors. The design of a compatible quiz in Moodle mobile app is performed with Moodle desktop platform only, the ability to create a quiz using Moodle mobile app is not supported yet. It is important to highlight that quizzes in Moodle mobile app are not supported in safe browsers. Quiz features available in Moodle mobile Quiz activity module are described below:

\subsection{Question types}

The Quiz activity module is used to design quizzes with question types compatible with mobile app. Standard Question types are suitable for mobile access and can be graded directly, such types are: (Calculated, calculated multi-choice, calculated simple, Drag and drop into text, Drag and drop markers, Drag and drop onto image, Description, Essay, Matching, Embedded Answers, Multiple choice, Short Answer, Numerical, Random short-answer matching, Select missing words and True/False). Essay questions which require uploading a file from student are manually graded.

Third-party questions are not compatible for mobile app quiz such as: Combined, and STACK types which need plugins to be installed. Also, the image is not supported in Moodle mobile quiz.

\subsection{Question bank}

The question bank or bool is available in Moodle mobile quiz to help instructor to assemble a record that contains all questions divided in categories. Question bank can be used to help instructor to select all or part of these questions when creating a quiz. The quiz will not be available in Moodle mobile app, if the quiz is designed by using a Question bank that has an incompatible mobile question type. In this case, the quiz must be performed through Moodle desktop.

\subsection{Question layout}

The design of a compatible quiz in Moodle mobile app is performed with Moodle desktop platform only. The Moodle mobile quiz support the ability to determine number of questions per page, as well as support reshuffling and randomizing the appearing of question. The attribute that prevent student to move to next question if the current question is not answered known as blocked question is not available in Moodle mobile quiz. 


\subsection{Quiz attempt}

The ability to validate the duration of online quiz attempt is supported. Instructor can determine the quiz duration from start-date/time to end-date/time. The quiz can be attempted after the start date/time only and must submitted before finish date/time. Instructor can determine number of times a student can attempts the quiz. Also, the time of quiz attempt is supported as well as the option to save for later and continue from last attempt. A massage will appear if the user tries to submit when connection lose or not connected to internet.

A remarkable feature is available which is the ability to download and attempt the quiz later offline. This is applicable if no time limit is set and no network address is required. Offline quiz is available through enabling the option "allow quiz to attempt offline in mobile app". When using offline the following options are not compatible: timer, access restriction by password or subnet, and the deferred feedback with or without CBM (Certainty-based marking).

\subsection{Quiz grade and rubric}

Both instructor and student can view grade for a quiz or for all course. Instructor can view the submission of quiz/assignment. also, student can see grade as weight and percentage, the total contribution of grade from all course are supported. Standard Question types are suitable for mobile access and can be graded directly except essay questions which require uploading a file from student and manual grading. For offline attempt; student can view the grade later since student can't submit the quiz offline, massage "finish but not submitted to the sit" is presented.

The instructor can write a feedback for student mark present in grade book, also the correct answer can be presented for students. A statistical report is provided for instructor for each question and the percent of answer for each choice made by students. Moodle mobile app provide an advance grading method; however, it does not apply a rubric to a mobile quiz. Rubrics are not yet supported.

\subsection{Quiz authentication}

Beside the course password, Instructor can create a password for the quiz to allow students to access the quiz. This process is performed during the design of the quiz. For security reasons, and to make sure that quiz is attempted from a certain network; IP network addresses will be considered. Quizzes in Moodle mobile app are not supported in safe browsers.

\section{Quiz Features in Blackboard Mobile LMS}

Blackboard is a proprietary LMS that support interactive teaching and learning across 90 countries reaching approximately 100 million users in over 30 languages (Blackboard, 2018). Blackboard provide two mobile applications designed for student 
and instructor. Students use Blackboard app to view course content and material, achieve assignment, quiz, interact with other student via massage or via discussion forum with the ability to receive notification and reminder. while Blackboard instructor app is available for teacher to view course material, grade of assignments, upload file and send massage to student.

The Blackboard app and instructor app are available on IOS 4.0+, Android 2.2+, and Windows devices. For best used, it is advisable to upgrade the application with the latest updated version for without any extra fees, if Blackboard is deployed by the institution.

The Mobile quiz is created by using Blackboard desktop environment only and can be accessed through mobile and /or browser desktop, till now you can't create the quiz through mobile device or via Blackboard instructor app (Blackboard 2018). Quiz features available in Blackboard Mobile Quiz activity module are described below:

\subsection{Question types}

Blackboard mobile quiz support many types of questions, such as: true/false, multiple choice, short answer, essay, Hot spot, File Response such that only image file types will be accepted by the Blackboard Mobile Learn app. We noticed that images in test questions are not displayed. Incompatible mobile questions within the quiz require either to open the test in a desktop browser or in the in-app browser. When you include incompatible mobile question types in a test, the app treats the test as mobile incompatible and a browser is needed. If all the questions in quiz are compatible, then the randomize of question and the answer are supported.

\subsection{Question bank}

Instructor can create, preview and update question in database and then instructor can use all or part of them. Question bank or bool questions can be reused in other quizzes. However, question bank or pool are supported in Blackboard mobile application if and only if it includes questions with supported types. Otherwise, quiz attempt will be performed using Blackboard learn environment in in-app browser or desktop browser.

\subsection{Question layout}

The Mobile quiz is created by using Blackboard learn desktop environment only. If all questions in quiz are mobile compatible, then randomizing of questions and answers is supported. Mobile appearance of questions in test; "One at a time question presentation" option that allow one question per page is not compatible in mobile quiz. 


\subsection{Quiz attempt}

The ability to set the duration of online quiz attempt is supported. Instructor can determine the quiz duration from start date/time to end date/time. The quiz can be attempted after the start date/time only and must be submitted before finish date/time. Instructor can determine number of times a student can attempt the quiz especially if it is self-assessment quiz. Timer option is not compatible with mobile quiz. However, the option "save for later" and continue from last session is available. The message " you can't save for later" will appear, if instructor prevents this option and requires submitting quiz with the first quiz attempt.

In Blackboard, attempting quiz offline is not supported. Student can view course contents, grades, feedback offline but cannot download quiz for offline attempt.

\subsection{Quiz grade and rubric}

Grade for overall course or for each quiz with feedback is supported. Blackboard app does not support feedback as attached file, new-box view annotation which is an inline grading comments, nor the response for each question answer feedback, these options are available only through desktop browser. The score of each question in quiz (correct or not) is not supported in mobile quiz.

Instructor can choose to enter the grade via grade forum discussion or individual discussion, and then student can see his/her grade with instructor feedback.

In the app, quiz rubrics are supported. Instructor can associate a rubric with the quiz. Student can view the rubric, but they need to access the course on a web browser to see the scores the instructor selected for each criterion.

Blackboard instructor app provide the summary of number of students submitted and overall class average, results can be viewed in graph. Details of assessment is available, like number of attempts and if a rubric is used. Other options are provided like ready to grade, ready to post, posted grade and not submitted grade. However, grading test is not supported with instructor app. Instructor need Blackboard environment for grading. instructor can add comment for students as feedback for quiz when post grades.

\subsection{Quiz authentication}

Beside the course password, Instructor can create a password for the quiz to allow students to access the quiz. This process is performed during the design of the quiz.

\section{Discussion and Conclusion}

Blackboard applications and Moodle application are widely used in mobile learning. This paper is concentrated on quiz tool available in these applications based on features mentioned before. Blackboard have separate mobile applications for student and instructor while Moodle have one application for all. 
Both of the mobile applications share many quiz criteria: Moodle and blackboard have question bank for supported type of questions, Moodle app support more question types than Blackboard app. Moreover, layout feature is available for both under some restriction, and both support an unlimited time of attempt. if student did not finish the quiz the feature "save for later" is also supported in both mobile LMS. In addition, notification massage is used to remind students of a quiz is supported in Moodle and Blackboard, password for authentication is utilized in both applications.

Toward designing a quiz, instructor need to use desktop platform version for both Moodle and Blackboard. Unsupported questions in Blackboard app force student to open the quiz in app browser or desktop browser.

It is important to point that Moodle mobile quiz is not supported in safe browser. For un supported questions, student need to open desktop browser to complete the quiz.

Offline quiz feature is supported in Moodle app quiz; this feature can be defined as the ability to download a quiz to answer it later offline. this feature available only if the instructor activates the option "allow quiz to attempt offline in mobile app" when create a quiz, with offline quiz some features not work like timer, password, and the deferred feedback. The offline quiz not supported in Blackboard app.

Moodle app need to use plugins, which include 3 different types: Templates generated and downloaded when the user opens the plugins and Pure Java script plugins. The first type the template of plugin will be generated and download when user open the plugin in app. The second type Templates downloaded on login and rendered using JS data. Finally; Pure Java script plugins, this type need when you use feature like capture link in apps. If there is a question in quiz require a plugin not supported in the student's device the quiz will not work. While the users of blackboard apps do not need any plugins since they must use the latest edition.

In this paper, we have presented the relation between mobile learning, electronic learning and distance learning, and highlighted the features of quiz tool in Moodle app and blackboard app.

It is important to mention that cheating cannot be controlled in both apps unless the quiz is held in a closed room. Using mobile devices means that students are able to access downloadable course material and use them to answer the quiz. For future; we need to handle this issue to assure accurate quiz results.

\section{References:}

[1] Baran, E. (2014). A Review of Research on Mobile Learning in Teacher Education. Educational Technology \& Society, 17 (4), 17-32.

[2] Brink, J., 2011. M-learning: The future of training technology. ProQuest Education Journal.

[3] Dobre, I. (2015). Learning management systems for higher education - An overview of available options for higher education organizations. Procedia-Social and Behavioral Sciences, 180, 313-320. https://doi.org/10.1016/j.sbspro.2015.02.122

[4] El-Hussein, M. O. M., \& Cronje, J. C. (2010). Defining mobile learning in the higher education landscape. Journal of Educational Technology \& Society, 13(3), 12-21. 
[5] Georgiev T., Georgieva E., and A. (2004). M-Learning - a New Stage of E-Learning Smrikarov, International Conference on Computer Systems and Technologies - ompSysTech'2004, 4(28). https://doi.org/10.1145/1050330.1050437

[6] Ji, Z., Zhang, X., Ganchev, I., \& ODroma, M. (2013, July). Development of a senchatouch mtest mobile app for a mlearning system. In Advanced Learning Technologies (ICALT), 2013 IEEE 13th International Conference on (pp. 210-211). IEEE. https://doi.org/10.110 9/icalt.2013.64

[7] Kaiiali, M., Ozkaya, A., Altun, H., Haddad, M. H., \& Alier, M. (2016). Designing a secure exam management system (SEMS) for M-learning environments. https://doi.org/10.110 9/tlt.2016.2524570

[8] Kukulska-Hulme, A. (2009). Will mobile learning change language learning?. ReCALL, 21(2), 157-165. https://doi.org/10.1017/s0958344009000202

[9] Loomba, K., \& Loomba, P. (2009). Mobile learning in knowledge development scenario. DESIDOC Journal of Library \& Information Technology, 29(5), 54. https://doi.org/10.14 $\underline{429 / \text { djlit.29.270 }}$

[10] Marwan, M. E., Madar, A. R., \& Fuad, N. (2013). An overview of mobile application in learning for student of Kolej Poly-Tech Mara (KPTM) by using mobile phone. Journal of Asian Scientific Research, 3(6), 527.

[11] Meng, Z., \& Lu, J. (2011). Implementing the emerging mobile technologies in facilitating mobile exam system. IACSIT Press.

[12] Miguel Moneo, J., Caballé Llobet, S., Xhafa, F., \& Prieto Blázquez, J. (2015). Security in Online Web Learning Assessment. Providing an Effective Trustworthiness Approach to Support e-Learning Teams. https://doi.org/10.1007/s11280-014-0320-2

[13] Moore, J. L., Dickson-Deane, C., \& Galyen, K. (2011). e-Learning, online learning, and distance learning environments: Are they the same? The Internet and Higher Education, 14(2), 129-135. https://doi.org/10.1016/j.iheduc.2010.10.001

[14] Naismith, L., \& Corlett, D. (2006). Reflections on success: A retrospective of the mLearn conference series 2002-2005. In Across generations and cultures, mLearn 2006 book of abstracts (p. 118-20). Banff, Canada: mLearn 2006.

[15] Obeidallah, R., Al Ahmad, A., Farouq, F. and Awad, S. (2015) 'Students authentication in e-assessment sessions: a theoretical biometric model for smartphone devices', Int. J. Business Information Systems, Vol. 19, No. 4, pp.450-464. https://doi.org/10.1504/ijbis.20 15.070204

[16] Pankaja, N., \& Mukund Raj, P. K. (2013). Proprietary software versus open source software for education. American Journal of Engineering Research, 2(7), 124-130.

[17] Park, Y. (2011). A pedagogical framework for mobile learning: Categorizing educational applications of mobile technologies into four types. The International Review of Research in Open and Distributed Learning, 12(2), 78-102. https://doi.org/10.19173/irrodl.v12i2. $\underline{791}$

[18] Robles M. and BraathenS. (2002),” Online Assessment Techniques “, Delta Pi Epsilon Journal, VoL XLIV No. I Winter, 2002

[19] Rodrigues, J. R. A., Brandão, L. O., Nascimento, M., Rodrigues, P., Brandão, A. A., Giroire, H., \& Auzende, O. (2013, October). iQuiz: integrated assessment environment to improve Moodle Quiz. In Frontiers in Education Conference, 2013 IEEE (pp. 293-295). IEEE. https://doi.org/10.1109/fie.2013.6684834

[20] Romero, C., Ventura, S., \& De Bra, P. (2009). Using mobile and web-based computerized tests to evaluate university students. Computer Applications in Engineering Education, 17(4), 435-447. https://doi.org/10.1002/cae.20242 
[21] Sapargaliyev, D. (2012, November). Development of mobile learning in higher education of Russia. In Interactive Mobile and Computer Aided Learning (IMCL), 2012 International Conference on (pp. 48-51). IEEE. https://doi.org/10.1109/imcl.2012.6396449

[22] Sarrab, M., Elgamel, L., \& Aldabbas, H. (2012). Mobile learning (m-learning) and educational environments. International journal of distributed and parallel systems, 3(4), 31. https://doi.org/10.1115/1.860045 ch68

[23] Serafimov, L. (2013). Mobile learning platforms. The 9th International Scientific.

[24] Sindre, G., \& Vegendla, A. (2015). E-exams versus paper exams: a comparative analysis of cheating-related security threats and countermeasures. In Norwegian Information Security Conference (NISK) (Vol. 8, No. 1, pp. 34-45).

[25] Singh, V. (2015, December). Android based student learning system. In Computer Science and Engineering (APWC on CSE), 2015 2nd Asia-Pacific World Congress on (pp. 1-9). IEEE. https://doi.org/10.1109/apwccse.2015.7476228

[26] Singh, G., Antony, D. A., Leavline, E. J.,and Selvam, J. (2017). Mobile Application for mLearning. International Journal of Advanced Research in Computer Science, 8(3).

[27] Sukadarmika, G., Hartati, R. S., \& Linawati, N. P. S. (2018). Introducing TAMEx Model for Availability of E-Exam in Wireless Environment. methods, 2, 3. https://doi.org/10. 1109/icoiact.2018.8350741

[28] Tufekci, A., Ekinci, H., \& Kose, U. (2013). Development of an internet-based exam system for mobile environments and evaluation of its usability. Mevlana International Journal of Education, 3(4), 57-74. https://doi.org/10.13054/mije.13.59.3.4

[29] Wu, W. H., Wu, Y. C. J., Chen, C. Y., Kao, H. Y., Lin, C. H., \& Huang, S. H. (2012). Review of trends from mobile learning studies: A meta-analysis. Computers \& Education, 59(2), 817-827. https://doi.org/10.1016/j.compedu.2012.03.016

[30] Yao, X., and Ma, R. (2017). Design of Management System of Mobile Learning Platform. Management \& Engineering, (29), 8-14.

[31] Yu-mei, P., Xue-jun, Z., \& Li, L. (2010, March). Learning can happen anytime and anywhere: The application of m-learning in medical education. In Education Technology and Computer Science (ETCS), 2010 Second International Workshop on(Vol. 2, pp. 508-511). IEEE. https://moodle.net/stats/ https://blackboard.com https://doi.org/10.1109/etcs.201 $\underline{0.114}$

\section{Authors}

Aayat Shdaifat works as a Tutor in Basic Science, Department in The Hashemite University. She obtained her Masters in Computer Information System from Jordan University in 2009. Her research interests are involved in Services Composition, elearning and information system.

Randa Obeidallah works as a Tutor in Computer Information System Department in The Hashemite University. She obtained her Masters in Computer Information System from Jordan University in 2009. Her Research interests are involved in Information Retrieval, e-learning Systems, and Information systems.

Article submitted 2019-03-24. Resubmitted 2019-04-28. Final acceptance 2019-05-10. Final version published as submitted by the authors. 